\title{
A simple technique of unidirectional valved patch for closure of septal defects
}

\author{
Shiv Kumar Choudhary, MCh, Sachin Talwar, MCh, and Balram Airan, MCh, New Delhi, India
}

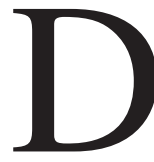
elayed presentation and operation for patients with atrial and ventricular septal defects and pulmonary hypertension are not uncommon in the developing world. $^{1,2}$ These patients often have a turbulent postoperative course as the result of pulmonary hypertension. To partially overcome this, a wide variety of unidirectional valved patches have been described. ${ }^{3-5}$ These serve to achieve a rightto-left shunt to prevent right ventricular failure in the setting of persistently elevated pulmonary artery pressures. We devised a simple technique for creating a unidirectional valved patch.

\section{Clinical Summary}

Routine monitoring, anesthesia, and cardiopulmonary bypass techniques are used. After cardioplegic arrest, the right atrium is opened and the atrial or ventricular septal defect is inspected and sized. A patch of knitted polyester fabric (Impra Inc, Tempe, Ariz) to match the width of the defect and approximately 1.5 times longer than the desired length is chosen, and a 4-mm fenestration is made in the patch using a standard aortic punch (Scanlan, St Paul, Minn). The patch is then folded on itself in such a way that after it is folded, the dimensions are adequate for closure of the septal defect. The flap created by the folding of the patch should cover the fenestration (Figure 1). One clip (LT 200 Ethicon Endosurgery, Cincinnati, Ohio) is placed on each side of the patch to hold the flaps together and facilitate suturing. The patch is then sutured to the edges of the septal defect using interrupted or continuous sutures in such a way that the flap lies toward the left ventricular side in patients with a ventricular septal defect and toward the left atrial side in patients with an atrial septal defect. As the sutures approach the clip, they are removed. Once the patch is sutured in place, routine deairing maneuvers are performed and the patient is weaned from cardiopulmonary bypass.

This technique has been successfully used by us in the last 2 years in patients who present late with atrial and ventricular septal defects and show evidence of borderline operability on preoperative investigations. Intraoperative transesophageal echocardiography and transthoracic echocardiography in the early postoperative phase demon-

From the Cardiothoracic Center, All India Institute of Medical Sciences, New Delhi, India.

Received for publication July 17, 2007; accepted for publication Aug 7, 2007.

Address for reprints: Shiv Kumar Choudhary, MCh, Department of Cardiothoracic and Vascular Surgery, All India Institute of Medical Sciences, New Delhi 110029, India (E-mail: shivchoudhary@hotmail.com).

J Thorac Cardiovasc Surg 2007;134:1357-8

$0022-5223 / \$ 32.00$

Copyright () 2007 by The American Association for Thoracic Surgery doi:10.1016/j.jtcvs.2007.08.003 strated right-to-left shunt through the fenestration, which gradually diminished. The patients recovered uneventfully.

\section{Discussion}

A variety of techniques have been described for the creation of unidirectional valved patches, ${ }^{3-5}$ but the techniques are often cumbersome and time-consuming. When the patches are fashioned before cardioplegic arrest and inspection of the defect, the sizing may be inaccurate. If they are fashioned after inspection of the defect, it adds to the cardioplegia time, because most often the fashioning of unidirectional patch requires 2 patches to be sutured. In the technique described here, less than 30 seconds are required for the patch sizing and preparation, thus reducing the cardioplegic arrest time. In contrast with other techniques that require the use of 2 patches (often 1 prosthetic and 1 pericardial patch), only 1 patch is required in this technique. Homografts were used in a recent study, ${ }^{5}$ but they had the disadvantages of limited availability and cost.

The technique described here is simple, easily reproducible, inexpensive, and less time-consuming, and does not require the use of

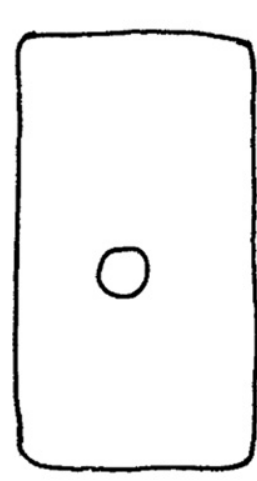

(a)

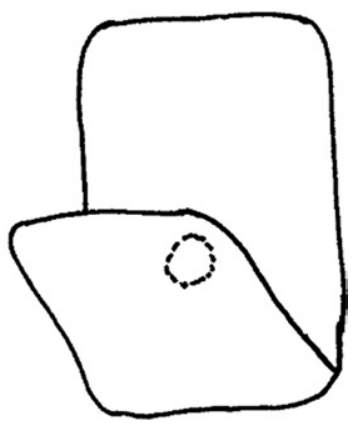

(b)

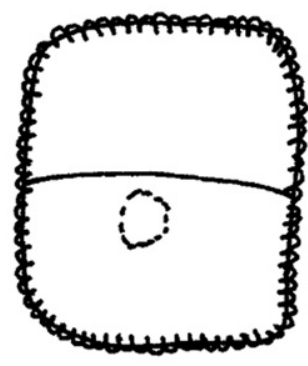

(c)

Figure 1. Technique of creating a unidirectional valved patch. An appropriately sized Dacron patch is selected (a), and a fenestration is made using an aortic punch. The patch is folded on itself (b) and sutured in place (c) as described in the text. 
additional material such as pericardium or homografts. It has been demonstrated to be effective in our early experience.

\section{References}

1. Health manpower requirements for the achievement of health for all by the year 2000 through primary health care. Report of a WHO Expert Committee. World Health Organ Tech Rep Ser. 1985;717:7-92.

2. Saxena A. Congenital heart disease in India. A status report. Ind J Pediatr. 2005;72:595-8.
3. Novick WM, Sandoval N, Lazorhysynets VV, Castillo V, Baskevitch A, Mo X, et al. Flap valve double patch closure of ventricular septal defects in children with increased pulmonary vascular resistance. Ann Thorac Surg. 2005;79:21-8.

4. Zhou Q, Lai $Y$, Wei H, Song R, Wu Y, Zhang H. Uidirectional valve patch for repair of cardiac septal defects with pulmonary hypertension. Ann Thorac Surg. 1995;60:1245-9.

5. Zhang B, Wu S, Liang J, Zhang G, Jiang G, Zhou M, et al. Unidirectional monovalve homologous aortic patch for repair of ventricular septal defect with pulmonary hypertension. Ann Thorac Surg. 2007;83: 2176-81

\section{The axillary incision: A cosmetic approach in congenital cardiac surgery}

Khanh Nguyen, MD, ${ }^{\text {a }}$ Cynthia Chin, MD, ${ }^{a}$ Dong-Seok Lee, MD, ${ }^{a}$ Alexander Mittnacht, MD, ${ }^{\text {b }}$ Shubikha Srivastava, MD, Joashi Umesh, MD, ${ }^{c}$ Steven Walker, RN, ${ }^{d}$ and David Adams, MD, ${ }^{a}$ New York, NY, and Paterson, NJ

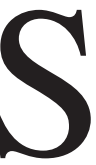

urgery for congenital heart disease has made great advances, and the focus has shifted from simply surviving the operation to the quality of life after surgical repair, especially when dealing with simple lesions such as atrial septal defects (ASDs). In children and young women, the appearance of the incision has been a significant issue, with concern that it could have an impact on the patient's psychological wellbeing and self esteem.

Several approaches have been described to avoid a visible midline scar. Most commonly, surgeons have tried using the anterolateral thoracotomy approach, originally described by Lewis and Taufic ${ }^{1}$ in 1952. In addition, there have been reports concerning the use of other access sites such as a short right lateral thoracotomy, posterolateral thoracotomy, ministernotomy, a subxiphoid approach without sternotomy, and, more recently, an axillary incision. ${ }^{2,3}$ The axillary incision scar is well concealed under the upper arm (Figure 1) and, in prepubescent female patients, poses less potential for subsequent breast tissue distortion. ${ }^{4}$ This article reports the use of the axillary incision at our institution in 34 patients with various congenital cardiac defects.

\section{Patients and Methods}

Thirty-four consecutive patients were included in the report. Median age was 5 years, with a range from 5 months to 47 years.

From the Departments of Cardiothoracic Surgery, ${ }^{\mathrm{a}}$ Anesthesiology, ${ }^{\mathrm{b}}$ and Pediatrics, ${ }^{\mathrm{c}}$ Mount Sinai Medical Center, New York, NY; and the Division of Pediatric Cardiology, ${ }^{\text {d }}$ St Joseph's Medical Center, Paterson, NJ.

Received for publication June 8, 2007; accepted for publication June 21, 2007.

Address for reprints: Khanh H. Nguyen, MD, Mount Sinai Medical Center, Department of Cardiothoracic Surgery, 1190 Fifth Ave, Box 1028, New York, NY 10029 (E-mail: Khanh.Nguyen@mountsinai.org).

J Thorac Cardiovasc Surg 2007;134:1358-60

$0022-5223 / \$ 32.00$

Copyright $\odot 2007$ by The American Association for Thoracic Surgery doi:10.1016/j.jtcvs.2007.06.033
Median weight was $21 \mathrm{~kg}$, with a range from 5.9 to $72 \mathrm{~kg}$. Clinical and operative data regarding the 34 patients are shown in Table 1.

We opted to evaluate the axillary incision against the commonly used incision, the ministernotomy. A subgroup of patients with secundum ASDs was compared with 14 other recent patients who had a secundum ASD closure through a ministernotomy incision. Their clinical data and the results of statistical analysis of this comparison are shown in Table 2.

Data gathering adhered to Mount Sinai and St Joseph's Medical Center Institutional Review Board guidelines. The protocol was approved by the Institutional Review Board, and specific patient consent was not required.

\section{Surgical Techniques}

Ministernotomy. The technique has been well described. ${ }^{5} \mathrm{~A}$ majority of patients had repair with the heart electrically fibrillated, and the defects were closed primarily. For larger lesions, the defects were closed with an autologous pericardial patch.

Right axillary incision. The patient was placed in the left lateral decubitus position. The right arm was elevated to expose the axilla. The slightly oblique incision was placed between the anterior and posterior axillary lines.

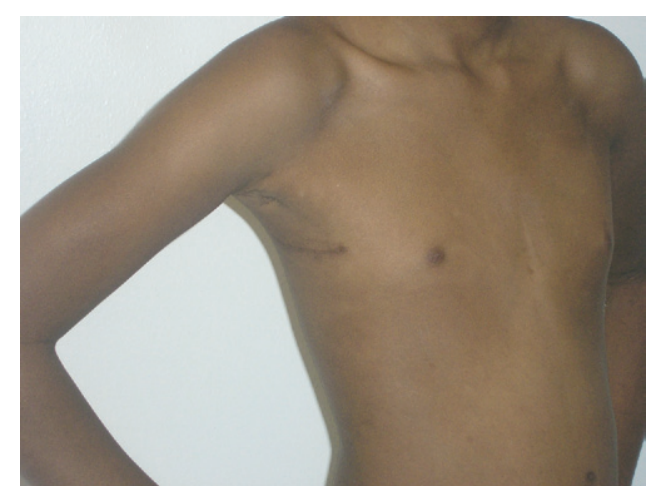

Figure 1. The scar for the axillary incision is positioned under the upper arm. 